\title{
Impact of residual and intrafractional errors on strategy of correction for image-guided accelerated partial breast irradiation
}

\author{
Gang Cai ${ }^{1+}$, Wei-Gang Hu${ }^{1 *}$, Jia-Yi Chen ${ }^{1 *}$, Xiao-Li Yu', Zi-Qiang Pan', Zhao-Zhi Yang ${ }^{1}$, Xiao-Mao Guo',
} Zhi-Min Shao ${ }^{2}$, Guo-Liang Jiang ${ }^{1}$

\begin{abstract}
Background: The cone beam $\mathrm{CT}$ (CBCT) guided radiation can reduce the systematic and random setup errors as compared to the skin-mark setup. However, the residual and intrafractional (RAIF) errors are still unknown. The purpose of this paper is to investigate the magnitude of RAIF errors and correction action levels needed in cone beam computed tomography (CBCT) guided accelerated partial breast irradiation (APBI).

Methods: Ten patients were enrolled in the prospective study of CBCT guided APBI. The postoperative tumor bed was irradiated with 38.5 Gy in 10 fractions over 5 days. Two cone-beam CT data sets were obtained with one before and one after the treatment delivery. The CBCT images were registered online to the planning $\mathrm{CT}$ images using the automatic algorithm followed by a fine manual adjustment. An action level of $3 \mathrm{~mm}$, meaning that corrections were performed for translations exceeding $3 \mathrm{~mm}$, was implemented in clinical treatments. Based on the acquired data, different correction action levels were simulated, and random RAIF errors, systematic RAIF errors and related margins before and after the treatments were determined for varying correction action levels.

Results: A total of 75 pairs of CBCT data sets were analyzed. The systematic and random setup errors based on skin-mark setup prior to treatment delivery were $2.1 \mathrm{~mm}$ and $1.8 \mathrm{~mm}$ in the lateral (LR), $3.1 \mathrm{~mm}$ and $2.3 \mathrm{~mm}$ in the superior-inferior (SI), and $2.3 \mathrm{~mm}$ and $2.0 \mathrm{~mm}$ in the anterior-posterior (AP) directions. With the $3 \mathrm{~mm}$ correction action level, the systematic and random RAIF errors were $2.5 \mathrm{~mm}$ and $2.3 \mathrm{~mm}$ in the LR direction, $2.3 \mathrm{~mm}$ and 2.3 $\mathrm{mm}$ in the SI direction, and $2.3 \mathrm{~mm}$ and $2.2 \mathrm{~mm}$ in the AP direction after treatments delivery. Accordingly, the margins for correction action levels of $3 \mathrm{~mm}, 4 \mathrm{~mm}, 5 \mathrm{~mm}, 6 \mathrm{~mm}$ and no correction were $7.9 \mathrm{~mm}, 8.0 \mathrm{~mm}, 8.0$ $\mathrm{mm}, 7.9 \mathrm{~mm}$ and $8.0 \mathrm{~mm}$ in the LR direction; $6.4 \mathrm{~mm}, 7.1 \mathrm{~mm}, 7.9 \mathrm{~mm}, 9.2 \mathrm{~mm}$ and $10.5 \mathrm{~mm}$ in the SI direction; $7.6 \mathrm{~mm}, 7.9 \mathrm{~mm}, 9.4 \mathrm{~mm}, 10.1 \mathrm{~mm}$ and $12.7 \mathrm{~mm}$ in the AP direction, respectively.

Conclusions: Residual and intrafractional errors can significantly affect the accuracy of image-guided APBI with nonplanar 3DCRT techniques. If a 10-mm CTV-PTV margin is applied, a correction action level of $5 \mathrm{~mm}$ or less is necessary so as to maintain the RAIF errors within $10 \mathrm{~mm}$ for more than $95 \%$ of fractions. Pre-treatment CBCT guidance is not a guarantee for safe delivery of the treatment despite its known benefits of reducing the initial setup errors. A patient position verification and correction during the treatment may be a method for the safe delivery.
\end{abstract}

\section{Background}

Several groups have shown that accelerated partial breast irradiation (APBI) for selected patients have comparable

\footnotetext{
* Correspondence: jackhuwg@hotmail.com; chenjiayi0188@yahoo.com.cn + Contributed equally

'Department of Radiation Oncology, Cancer Hospital, Department of Oncology, Shanghai Medical college, Fudan University, Shanghai, China Full list of author information is available at the end of the article
}

outcome to the standard whole breast irradiation after breast conservative surgery [1-3]. The three-dimensional conformal radiotherapy (3DCRT) has shown the advantages of noninvasive and easy implementation in a modern radiotherapy department $[4,5]$. According to the RTOG 0319 report [6], APBI has achieved similar early outcomes as whole-breast irradiation (WBI). Various

\section{() Biomed Central}


techniques have been adopted in the 3DCRT, including the multiple noncoplanar field technique, three-field mixed modality technique and proton therapy [7-12].

Compared to WBI, APBI requires more accuracy because the highly conformal dose is delivered to a relatively small area. The cone beam CT (CBCT) guided radiation therapy has been used to reduce the probability of geographical displacements in different sites [13-19]. White et al. reported that CBCT guided setup with an action level of $3 \mathrm{~mm}$ could reduce the systematic and random setup errors as compared to the skinmark setup[20], but no data on intra-fractional error was reported. Also, some errors would still exist after the couch shift, which are named as residual errors, therefore, it is unclear whether the magnitude of residual and intrafractional errors would significantly affect the correction levels and the appropriate planning target margins. This is especially necessary for APBI treated with noncoplanar fields. We therefore investigated the magnitude of residual and intrafractional errors with various pre-treatment correction action levels so as to determine the appropriate margins needed for $\mathrm{CBCT}$ guided APBI with noncoplanar 3DCRT techniques.

\section{Methods}

\section{Patient eligibility}

From July 2008 to December 2008, ten patients were enrolled in a prospective, single institutional review board-approved trial of APBI with CBCT imaging guidance. The eligibility criteria included: age $\geq 45$ years, Stage T1N0M0 or Stage Tis, negative surgical margins $(\geq 2 \mathrm{~mm}$ ) after definitive surgery, and at least 4 titanium clips were placed in the resection cavity. The median age of the 10 enrolled patients was 55 (45-75). Four patients were diagnosed with ductal carcinoma in situ (DCIS), and the remaining 6 were diagnosed with invasive ductal carcinoma. One patient had the tumor on the right side, and the other 9 had their tumors on the left-side. Three patients (including one with DCIS) underwent sentinel lymph nodes biopsy, 4 patients with invasive carcinoma had axillary nodes dissection, and the other 3 DCIS had no axillary surgery. The primary tumor was located in the upper-outer quadrant in 3 patients, in the inner-upper quadrant in 4 patients and in the central or aerolar region in other 3 patients.

\section{Target delineation and treatment planning}

All patients were immobilized using a Med-Tec 350 breastboard (Med-Tec Corporation, Orange, IA, USA) with both arms raised above their heads. CT images were acquired with 5-mm-thick intervals from the level of mandible through the lung base using a Philips big core CT scanner (Philips Medical Madison, Fitchburg, WI, USA). All CT images were exported to the Pinnacle treatment planning system (Philips Radiation Oncology Systems, Pinnacle version 8.0, Milpitas, CA) for contouring and treatment planning.

The lumpectomy/surgical cavity, ipsilateral breast, contralateral breast, lungs, heart, clinical target volume (CTV) and planning target volume (PTV) were segmented in the CT images. The CTV was the surgical cavity defined by clips and seroma plus a margin of $10 \mathrm{~mm}$. An additional margin of $10 \mathrm{~mm}$ was placed around CTV to define PTV. Both CTV and PTV were limited to $5 \mathrm{~mm}$ from the skin surface and $5 \mathrm{~mm}$ from the lung-chest interface following the RTOG 0319 guideline. The ipsilateral and contralateral breasts were contoured with all the visible breast tissue on CT images, which extends from the infra-mammary fold to the head of clavicle in the cranial-caudal direction. The heart was contoured from the first CT slice below the pulmonary artery to the apex inferiorly. Both lungs were contoured in their entirety.

A 3DCRT technique using 6MV photons with 5-field non-coplanar beam arrangement was developed. The arrangement used fields that approximate breast tangents with a 15-20 degree steeper gantry angle for medial beams and couch angles of 15-70 degrees, similar to the report of Baglan et al.[12]. The treatment plans were manually optimized such that more than $95 \%$ of PTV was completely encompassed by the $95 \%$ isodose line, while maintaining a minimum dose greater than $93 \%$ and a maximum dose less than $110 \%$. The dose prescription was 38.5 Gy delivered in 10 fractions, with a total duration of 5-7 days. The treatment was delivered twice daily with an interfractional interval of at least 6 hours.

The tolerances of normal tissues were defined as follows: 1 ) less than $10 \%$ of the ipsilateral lung receiving $30 \%$ of the prescribed dose $(\mathrm{V}-10 \%<30 \%), 2)$ less than $10 \%$ of the contralateral lung receiving $5 \%$ of the prescribed dose, 3) less than $5 \%$ of the heart receiving 5\% of the prescribed dose for right-sided patients, and 4) the volume of the heart receiving $5 \%$ of the prescribed dose should be below that for whole breast irradiation for patients with left-sided tumors.

All treatments were delivered with an Elekta Synergy S linear accelerator equipped with an electronic portal imaging device (EPID) and a kilovoltage cone-beam CT system (Elekta Synergy S, Elekta Oncology Systems, Crawley, UK). Three skin markers corresponding to the laser in the treatment room were used for initial setup.

\section{kVCBCT images acquisition and registration}

Two kVCBCT imaging protocols were created separately for the left and right breast tumors. Both protocols had the parameters of F0 filter, S20 collimator, $120 \mathrm{kV}, 36.1$ mA-s and Med_Res reconstruction. The acquisition 
angles range from $250^{\circ}$ to $90^{\circ}$ (clockwise) for the left breast tumors and from $180^{\circ}$ to $30^{\circ}$ (clockwise) for the right breast tumors.

The first CBCT images were acquired immediately after positioning the patients with 3 skin markers. The $\mathrm{CBCT}$ images were first automatically registered to the planning $\mathrm{CT}$ using the grey value algorithm implemented in the XVI software (XVI, version 3.5 b147) followed by a manual fine adjustment to get a better match on chest wall, clips and skin in the axial, coronal and sagittal planes. All the online registration was done within 2-3 minutes by the same radiation oncologist. The isocenter was used as the correction reference point and all the rotational errors were disregarded. A couch shift was applied if the required shift was greater than $3 \mathrm{~mm}$ in any of the three directions. This threshold was designated as the $3 \mathrm{~mm}$ correction action level (3 mmCAL). Two therapists shifted the couch to the required position indicated by the XVI software, and the couch position was double checked by the radiation oncologist. A post-treatment CBCT with the same parameters was acquired after the treatment delivery. The same radiation oncologist performed the identical registration process and recorded the results.

\section{Correction action levels}

The residual and intrafraction (RAIF) errors with the 3 mmCAL can be obtained directly from the first and second CBCT images. In addition, we simulated the hypothetical RAIF errors with increasing correction action levels $(\mathrm{CAL})$ at $4 \mathrm{~mm}$ CAL, $5 \mathrm{mmCAL}, 6$ mmCAL and no correction (skin markers only). The process applied was:

(1) Register the first CBCT images (named CBCT1) with planning $\mathrm{CT}$ images and record the shifts in the lateral (LR), superior-inferior (SI) and anterior-posterior (AP) directions.

(2) Calculate and simulate the residual errors with different action levels after couch shift. In the $3 \mathrm{mmCAL}$ (as with $4 \mathrm{~mm}, 5 \mathrm{~mm}$ and $6 \mathrm{mmCAL}$ ), any required shifts larger than $3 \mathrm{~mm}(4 \mathrm{~mm}, 5 \mathrm{~mm}$ and $6 \mathrm{~mm})$ in any of the three directions will be set to zero and then saved in a new data set named 3 mmresidual $(4$ mmresidual, 5 mmresidual and 6 mmresidual). For example, if the results from the first registration were $3.5,5$ and 2 $\mathrm{mm}$ in the LR, SI and AP directions respectively, the 3 mmresidual would be 0,0 and $2 \mathrm{~mm}$ and the 4 mmresidual would be $3.5,0$ and $2 \mathrm{~mm}$.

(3) Register the post-treatment CBCT images (CBCT2) with planning $\mathrm{CT}$ and record the second shifted dataset in the LR, SI and AP directions.

(4) Calculate the intrafractional error (named Intraerror) using CBCT2 minus 3 mmresidual. In principle, the intrafractional error is independent of the correction levels.
(5) The residual and intrafractional (RAIF) errors in $3 \mathrm{mmCAL}$ and other hypothetical correction action levels ( $4 \mathrm{~mm}, 5 \mathrm{~mm}, 6 \mathrm{mmCAL}$ and nocorrection) were calculated by summing up the 4 mmresidual, 5 mmresidual, 6 mmrediual and nocorrection with Intraerror, respectively.

For each patient, the mean value and standard deviation(SD) of RAIF error for different correction action levels were calculated. The population systematic RAIF errors $\left(\Sigma_{\text {RAIF }}\right)$ were calculated from the SD of all the means. The random errors $\left(\delta_{\text {RAIF }}\right)$ were calculated from the root mean square (RMS) of all the SDs [21]. The related margins were calculated using the following equation:

$$
\text { Margin }=2.5 \sum_{\text {RAIF }}+0.7 \delta_{\text {RAIF }}
$$

which is reported by Van Herk[22]. For the analysis of different CALs, the $3 \mathrm{mmCAL}$ was used as reference and compared with other CALs using t-test.

\section{Results}

Of the ten patients, five had $\mathrm{CBCT}$ images for each fraction, and the others five had CBCT images every other fraction due to the limitation of machine availability. A total of $150 \mathrm{CBCT}$ image data sets were collected, with 75 before treatment and 75 after treatment.

\section{Setup errors from the first $\mathrm{CBCT}$}

All initial setup errors based on skin markers were within $10 \mathrm{~mm}$. Table 1 summarizes the systematic, random setup errors and margins for the different correction action levels. The margins were calculated using the same equation as described in the previous section [22]. The systematic and random setup errors for positioning patient with skin markers were $2.1 \mathrm{~mm}$ and 1.8 $\mathrm{mm}$ in the LR direction, $3.1 \mathrm{~mm}$ and $2.3 \mathrm{~mm}$ in the SI direction and $2.3 \mathrm{~mm}$ and $2.0 \mathrm{~mm}$ in the AP direction. Thus, the margins for skin markers setup were $6.5 \mathrm{~mm}$, $9.4 \mathrm{~mm}$ and $7.2 \mathrm{~mm}$ in the LR, SI and AP directions, respectively.

Both the systematic and random setup errors showed a decrease in magnitude with stricter action levels. The maximum systematic errors decreased from $3.1 \mathrm{~mm}$ (nocorrection) to $0.9 \mathrm{~mm}$ ( $3 \mathrm{mmCAL})$; and the maximum random errors decreased from $2.3 \mathrm{~mm}$ (nocorrection) to $1.1 \mathrm{~mm}$ ( $3 \mathrm{mmCAL})$. Compared to the random errors, the systematic errors presented a larger decrease with stricter action levels.

\section{Errors detected by the post-treatment $\mathrm{CBCT}$ images and corresponding margins}

For the whole group, the mean and SD for the Intraerror is $1.5 \pm 2.6 \mathrm{~mm}$ in the LR direction, $0.1 \pm 2.6 \mathrm{~mm}$ 
Table 1 The systematic and random setup errors and setup margins in the lateral (LR), superior-inferior (SI) and anterior-posterior (AP) directions with different correction action levels (CALs)(based on the 75 pre-treatment CBCT data sets)

\begin{tabular}{|c|c|c|c|c|c|c|c|c|c|}
\hline \multirow[t]{2}{*}{ CAL } & \multicolumn{3}{|c|}{ LR } & \multicolumn{3}{|c|}{ SI } & \multicolumn{3}{|c|}{ AP } \\
\hline & $\begin{array}{c}\text { Systematic } \\
\text { setup error } \\
(\mathrm{mm})\end{array}$ & $\begin{array}{l}\text { Random } \\
\text { setup error } \\
(\mathrm{mm})\end{array}$ & $\begin{array}{c}\text { Margin } \\
(\mathrm{mm})\end{array}$ & $\begin{array}{c}\text { Systematic } \\
\text { setup error } \\
(\mathrm{mm})\end{array}$ & $\begin{array}{l}\text { Random } \\
\text { setup error } \\
(\mathrm{mm})\end{array}$ & $\begin{array}{c}\text { Margin } \\
(\mathrm{mm})\end{array}$ & $\begin{array}{c}\text { Systematic } \\
\text { setup error } \\
(\mathrm{mm})\end{array}$ & $\begin{array}{l}\text { Random } \\
\text { setup error } \\
(\mathrm{mm})\end{array}$ & $\begin{array}{c}\text { Margin } \\
(\mathrm{mm})\end{array}$ \\
\hline $3 \mathrm{mmCAL}$ & 0.9 & 1.2 & 3.1 & 0.9 & 1.4 & 3.2 & 0.7 & 1.1 & 2.5 \\
\hline $4 \mathrm{mmCAL}$ & 1.1 & 1.5 & 3.8 & 1.2 & 1.7 & 4.2 & 0.9 & 1.2 & 3.1 \\
\hline $5 \mathrm{mmCAL}$ & 1.3 & 1.6 & 4.4 & 1.7 & 1.9 & 5.6 & 1.5 & 1.6 & 4.9 \\
\hline $6 \mathrm{mmCAL}$ & 1.6 & 1.8 & 5.3 & 2.1 & 1.9 & 6.6 & 1.9 & 1.6 & 5.9 \\
\hline nocorrection & 2.1 & 1.8 & 6.5 & 3.1 & 2.3 & 9.4 & 2.3 & 2.0 & 7.2 \\
\hline
\end{tabular}

in the SI direction and $-0.8 \pm 2.6 \mathrm{~mm}$ in the AP direction. The RAIF errors at actual $3 \mathrm{mmCAL}$ and hypothetical CALs were then calculated.

Figure 1 shows the distribution of RAIF errors. Most of the RAIF errors (94.8\%) were within $7.0 \mathrm{~mm}$ in the 3 mmCAL. For the total 75 fractions, at the $3 \mathrm{mmCAL}$ and $4 \mathrm{mmCAL}$, all RAIF errors were within $10 \mathrm{~mm}$ except in 3 ( 2 in the LR direction and 1 in the AP direction). At $5 \mathrm{mmCAL}, 6 \mathrm{mmCAL}$ and nocorrection, the number of fractions with RAIF errors in one direction of $10 \mathrm{~mm}$ or above were 3,4 , and 7 respectively.

Table 2 shows the systematic, random RAIF errors and corresponding margins to the different CALs. Similar to the results in the pretreatment CBCT images with skin marker setup, stricter action levels resulted in smaller RAIF errors, except for the LR direction which was not statistically significant $(P>0.05)$. In the AP direction, the increase in the systematic RAIF error from 3 $\mathrm{mmCAL}$ to $4 \mathrm{mmCAL}, 5 \mathrm{mmCAL}, 6 \mathrm{mmCAL}$ and nocorrection was statistically significant $(\mathrm{p}=0.04,0.00$, $0.00,0.00$, respectively). In the SI direction, however, statistical difference of the increase of systemic error was only found when the $3 \mathrm{mmCAL}$ was increased to 6 mmCAL and nocorrection $(\mathrm{p}=0.026$ and 0.021 , respectively).

Based on the $3 \mathrm{mmCAL}$, the CTV-PTV margins with $7.9 \mathrm{~mm}$ in the LR, $6.4 \mathrm{~mm}$ in the SI and $7.3 \mathrm{~mm}$ in the AP direction were required to compensate for the RAIF errors. Maximum CTV-PTV margin was $<10 \mathrm{~mm}$ in all directions for the $3 \mathrm{mmCAL}, 4 \mathrm{mmCAL}$ and $5 \mathrm{mmCAL}$; $10.2 \mathrm{~mm}$ in the AP direction for the $6 \mathrm{mmCAL} ; 12.7$ $\mathrm{mm}$ in the AP direction for nocorrection (table 2). For the total $75 \mathrm{CBCT}$ image data sets, the percentage of fractions with shifts smaller than $10 \mathrm{~mm}$ in any of the directions were $97.3 \%, 97.3 \%, 96 \%, 94.7 \%$, and $90.7 \%$ for $3 \mathrm{mmCAL}, 4 \mathrm{mmCAL}, 5 \mathrm{mmCAL}, 6 \mathrm{mmCAL}$ and nocorrection, respectively.

\section{Discussion}

In this study, we calculated the RAIF errors and corresponding margins with different correction action levels in the CBCT guided APBI. We found that long treatment time and couch rotation in external beam APBI delivery may affect the accuracy of treatment delivery.

APBI using 3-D CRT has demonstrated its superiority in target coverage and dose homogeneity compared with brachytherapy. In order to minimize the unnecessary irradiation to normal tissues, efforts should be made as to reduce the set-up errors and intra-fractional motion, which are two major components in determining the optimal margin. Pretreatment CBCT is helpful in reducing the initial set-up error, while it is not sufficient to determine which margin should be applied as residual error and intra-fractional motion may have their impact on treatment accuracy.

Overall, we found the initial setup margins were 6.5, 9.4 and $7.2 \mathrm{~mm}$ in the LR, SI and AP directions, respectively. White et al. reported the systematic setup error based on the skin-marker setup were $2.7,2.4$, and 1.7 $\mathrm{mm}$ and random errors were 2.4, 2.9 and $2.2 \mathrm{~mm}$ in the LR, SI and AP directions, respectively [20], which made the total setup margins of $8.4 \mathrm{~mm}, 8.0 \mathrm{~mm}$ and $5.8 \mathrm{~mm}$ in the LR, SI and AP direction respectively. Both their data and our study have shown that the $10 \mathrm{~mm}$ setup margin is feasible for skin-marker setup without considering the residual and intra-fractional motions. Also, they reported that the systematic and random setup errors could be reduced to 0.8 and $1.5 \mathrm{~mm}$ in the LR direction, 0.7 and $1.6 \mathrm{~mm}$ in the SI direction and 0.8 and $1.5 \mathrm{~mm}$ in the AP direction with the $3 \mathrm{mmCAL}$ in the CBCT guidance, respectively. By testing the magnitude of error with different CALs, a correlation of increased error with increasing CALs was found. Further to their study, we wish to find the impact of different CALs on overall residual and intro-fractional errors, which constitute a more reasonable prediction on CTVPTV margin. We did not start with CALs less than 3 $\mathrm{mm}$ as it has been proved that no further reduction of set-up errors could be found when smaller CALs were applied.

Evidently, the implementation of CBCT imaging is important in reducing the initial patient setup errors 

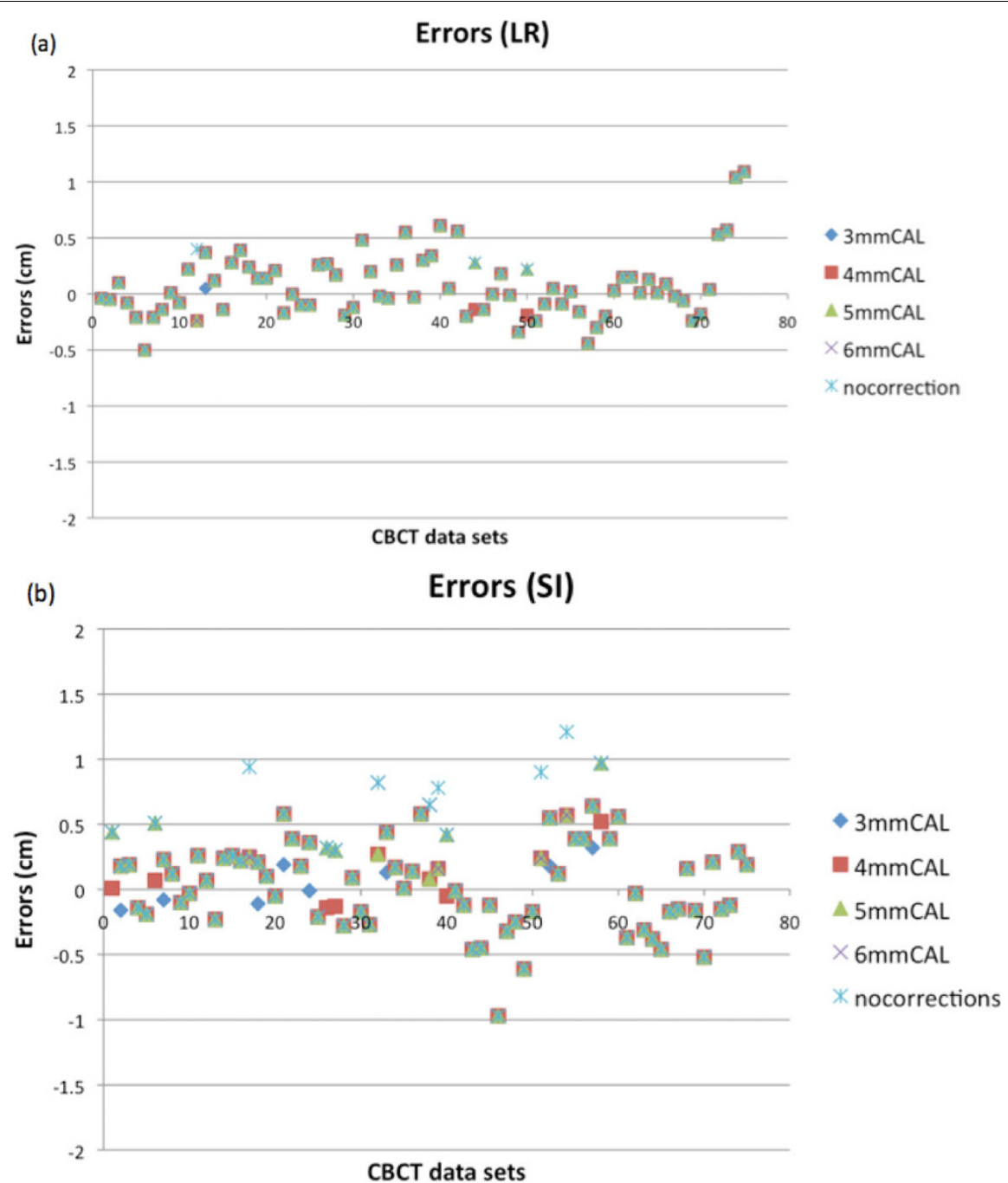

(c)

Errors (AP)

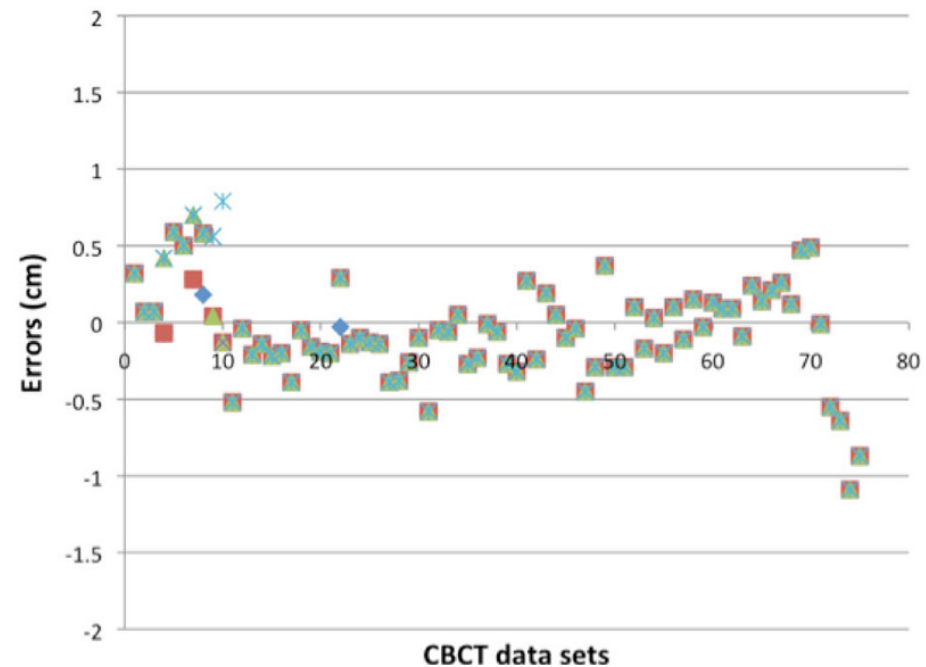

४ 3mmCAL

ammCAL

$\triangle 5 \mathrm{mmCAL}$

$\times 6 \mathrm{mmCAL}$

* nocorrection

CBCT data sets

Figure 1 The distributions of detected and calculated errors based on the $2^{\text {nd }} C B C T$ images for different correction action levels (CALs). (a), (b) and (c) show the detected errors in the LR, SI and AP directions, respectively. 
Table 2 The systematic, random RAIF errors and corresponding margins in the lateral (LR), superior-inferior (SI) and anterior-posterior (AP) directions with different correction action levels (CALs)

\begin{tabular}{|c|c|c|c|c|c|c|c|c|c|}
\hline \multirow[t]{2}{*}{ CAL } & \multicolumn{3}{|c|}{ LR } & \multicolumn{3}{|c|}{ SI } & \multicolumn{3}{|c|}{ AP } \\
\hline & $\begin{array}{c}\text { Systematic } \\
\text { RAIF error }(\mathrm{mm})\end{array}$ & $\begin{array}{c}\text { Random RAIF } \\
\text { error }(\mathrm{mm})\end{array}$ & $\begin{array}{c}\text { Margin } \\
(\mathrm{mm})\end{array}$ & $\begin{array}{c}\text { Systematic } \\
\text { RAIF error }(\mathrm{mm})\end{array}$ & $\begin{array}{l}\text { Random RAIF } \\
\text { error }(\mathrm{mm})\end{array}$ & $\begin{array}{c}\text { Margin } \\
(\mathrm{mm})\end{array}$ & $\begin{array}{c}\text { Systematic } \\
\text { RAIF error }(\mathrm{mm}) \\
\end{array}$ & $\begin{array}{l}\text { Random RAIF } \\
\text { error }(\mathrm{mm})\end{array}$ & $\begin{array}{c}\text { Margin } \\
(\mathrm{mm})\end{array}$ \\
\hline $3 \mathrm{mmCAL}$ & 2.5 & 2.3 & 7.9 & 2.0 & 2.0 & 6.4 & 2.3 & 2.2 & 7.3 \\
\hline $4 \mathrm{mmCAL}$ & 2.5 & 2.5 & 8.0 & 2.2 & 2.3 & 7.1 & 2.5 & 2.5 & 8.0 \\
\hline $5 \mathrm{mmCAL}$ & 2.4 & 2.9 & 8.0 & 2.5 & 2.5 & 8.0 & 3.0 & 2.9 & 9.5 \\
\hline $6 \mathrm{mmCAL}$ & 2.3 & 3.1 & 7.9 & 2.9 & 2.8 & 9.2 & 3.3 & 2.8 & 10.2 \\
\hline nocorrection & 2.3 & 3.1 & 7.9 & 3.3 & 3.2 & 10.5 & 4.3 & 2.8 & 12.7 \\
\hline
\end{tabular}

$[20,23]$. Margins with $3 \mathrm{mmCAL}$ before treatment were almost half to those with no correction. However, after treatment delivered with $3 \mathrm{mmCAL}$, the systematic RAIF errors were $2.5,2.0$ and $2.3 \mathrm{~mm}$ and the random RAIF errors were $2.3,2.0$ and $2.2 \mathrm{~mm}$ in the LR, SI and AP directions, respectively, which were almost similar to the skin-marker setup error detected by pretreatment CBCT images. Such significant changes confirm our hypothesis that the long treatment time and couch rotation can diminish the benefit of pretreatment image guidance. Position verification and correction during the treatment delivery may reduce these errors. The treatment position in our study was both arms raised symmetrically above the patient's head, thus, the chance of LR displacement maybe less than in the AP and SI directions, which were influenced by the respiration and the minor deviation of arm abduction angle, respectively. Therefore, we did not observe a statistical difference of RAIF change with increased CALs in the LR direction.

Based on the formula of Van Herk et al.[22], the margins in the LR, SI and AP directions for the skin marker setup were 6.5,9.4 and $7.2 \mathrm{~mm}$ with the data of pretreatment CBCT images, while increased to 7.9,10.5 and 12.7 $\mathrm{mm}$ when post-treatment $\mathrm{CBCT}$ data were integrated. This finding suggests that the skin marker setup is not sufficient for the safe delivery of APBI if 10-mm CTV to PTV setup margin is used. Instead, a CTV to PTV margin of at least $13 \mathrm{~mm}$ is necessary to account for both the initial setup errors and intrafractional errors. A10$\mathrm{mm}$ CTV to PTV margin can be used if the online CBCT guided correction is performed with CALs of 5 $\mathrm{mm}$ or smaller for guaranteeing $95 \%$ of the fractions have the RAIF errors within $10 \mathrm{~mm}$.

The image registration plays an important role in evaluating the setup errors. Three registration algorithms are implemented in the XVI system: manual, bone and grey. The details of the algorithms have been well described $[18,24]$. Although the grey algorithm method can achieve a good registration, some fine adjustments are still helpful in most fractions. In this study we combined the automatic grey algorithm method with fine manual adjustment. Baglan et al. demonstrated a strong correlation between the chest wall or rib position and clip position [12]. Weed et al. showed that clips were good radiographic surrogate for the lumpectomy cavity in the image-guided APBI[25]. Topolnjak et al. reported that the uncertainties in the position of the excision cavity could be reduced by using registration of the breast surface[26]. Considering the short treatment duration, we did not study specifically the deformation of breast and surgical cavity between planning $\mathrm{CT}$ and CBCTs, and we combined the information of chest wall, clips and skin as the parameters of registration.

One limitation of the current study is that we did not acquire CBCT images after correction; instead we used a method of calculating the result by assuming the 3 mmCAL. The calculated systematic and random setup errors were 0.9 and $1.2 \mathrm{~mm}$ in the LR direction, 0.7 and $1.4 \mathrm{~mm}$ in the SI direction and 0.7 and $1.1 \mathrm{~mm}$ in the AP direction, which had a good agreement to White's residual errors [23]. This confirms the feasibility of using such method for residual errors calculation. Moreover, any residual error with different CALs in one patient can only be tested instead of being measured. The post-treatment CBCT data set had the information of both the residual and intrafraction errors, thus it is reasonable to remove the residual errors to get the intrafractional errors. Another limitation is that we did not integrate the information from rotational errors due to the limitation of the current treatment couch. Although we postulate the actual margins may be less if rotational errors will be corrected, we have no data to confirm that until the result of our further study which will focus on the rotational errors after the installation of 6-degree couch.

Both planning $\mathrm{CT}$ and $\mathrm{CBCT}$ in our study were acquired in free breathing mode, therefore, the setup errors observed here also accounted for respiratory motion. Baglan et al. showed that a CTV to PTV margin of $10 \mathrm{~mm}$ was sufficient for most patients treated with APBI in free breathing [9]. Further to their findings, after we had analyzed in detail the 75 sets of CBCT images, we found that a $10-\mathrm{mm}$ CTV to PTV margin is 
sufficient for more than $95 \%$ of fractions with CAL of 5 $\mathrm{mm}$ or less if the residual and intrafractional errors are considered. Actually, the margins would be larger if the potential impacts of breast and tumor bed deformation and delineation errors were involved, but these need further investigation. A CTV to PTV margin of more than $10 \mathrm{~mm}$ is required to maintain the desired target coverage for the $6 \mathrm{mmCAL}$ or skin marker setup.

\section{Conclusion}

Residual and intrafractional errors can significantly affect the accuracy of image-guided APBI with nonplanar 3DCRT techniques. The 10-mm margin for skin marker setup was found inadequate for such techniques. A correction action level of $5 \mathrm{~mm}$ or less is required to maintain the RAIF errors within $10 \mathrm{~mm}$ for more than 95\% of fractions. Pre-treatment CBCT guidance is not a guarantee for safe delivery of such treatment despite its known benefits of reducing initial patient setup errors. A patient position verification and correction during the treatment may be a method for the safe treatment delivery Further investigations are ongoing to evaluate the dosimetrical effects of these action levels.

\section{Acknowledgements}

The authors thank Dr. Andrew Hwang and Dr. Lijun Ma in the Department of Radiation Oncology, University of California San Francisco, for helpful discussions and editing of the paper.

\section{Author details}

${ }^{1}$ Department of Radiation Oncology, Cancer Hospital, Department of Oncology, Shanghai Medical college, Fudan University, Shanghai, China. 2Department of Breast Surgery, Cancer Hospital, Department of Oncology, Shanghai Medical college, Fudan University, Shanghai, China.

\section{Authors' contributions}

GC and JYC carried out conception and design, target delineations, image registration, collection and assembly of data, data analysis, manuscript writing. WGH carried out study design, the treatment planning, image registation procedure, data analysis and interpretation, manuscript writing. XLY and ZQP took care of patients. ZZY, XMG, ZMS and GLJ gave advice on the work and participated in study design. All authors read and approved the final manuscript.

\section{Competing interests}

The authors declare that they have no competing interests.

Received: 23 June 2010 Accepted: 26 October 2010 Published: 26 October 2010

\section{References}

1. Wadasadawala T, Sarin R, Budrukkar A, Jalali R, Munshi A, Badwe R: Accelerated partial-breast irradiation vs conventional whole-breast radiotherapy in early breast cancer: A case-control study of disease control, cosmesis, and complications. J Cancer Res Ther 2009, 5:93-101.

2. Chen PY, Wallace M, Mitchell C, Grills I, Kestin L, Fowler A, Martinez A, Vicini F: Four-year efficacy, cosmesis, and toxicity using threedimensional conformal external beam radiation therapy to deliver accelerated partial breast irradiation. Int J Radiat Oncol Biol Phys 2010, 76:991-7.

3. Polgár C, Major T, Fodor J, Sulyok Z, Somogyi A, Lövey K, Németh G, Kásler M: Accelerated partial-breast irradiation using high-dose-rate interstitial brachytherapy: 12-year update of a prospective clinical study. Radiother Oncol 2010, 94:274-279.

4. Patel RR, Becker SJ, Das RK, Mackie TR: A dosimetric comparison of accelerated partial breast irradiation techniques: multicatheter interstitial brachytherapy, three-dimensional conformal radiotherapy, and supine versus prone helical tomotherapy. Int J Radiat Oncol Biol Phys 2007, 68:935-42.

5. Cuttino LW, Todor D, Pacyna L, Lin PS, Arthur DW: Three-dimensional conformal external beam radiotherapy (3D-CRT) for accelerated partial breast irradiation (APBI): what is the correct prescription dose? Am J Clin Oncol 2006, 29:474-78.

6. Vicini F, Winter K, Straube W, Wong J, Pass H, Rabinovitch R, Chafe S, Arthur D, Petersen I, McCormick B: Initial Efficacy Results of RTOG 0319: Three Dimensional Conformal Radiation Therapy (3D-CRT) Confined to the Region of the Lumpectomy Cavity for Stage I/II Breast Carcinoma. Int J Radiat Oncol Biol Phys 2010, 77:1120-1127.

7. Kozak KR, Katz A, Adams J, Crowley EM, Nyamwanda JA, Feng JK, Doppke KP, Delaney TF, Taghian AG: Dosimetric comparison of proton and photon three-dimensional, conformal, external beam accelerated partial breast irradiation techniques. Int J Radiat Oncol Biol Phys 2006, 65:1572-78.

8. Vicini FA, Chen P, Wallace M, Mitchell C, Hasan Y, Grills I, Kestin L, Schell S, Goldstein NS, Kunzman J, Gilbert S, Martinez A: Interim cosmetic results and toxicity using 3D conformal external beam radiotherapy to deliver accelerated partial breast irradiation in patients with early-stage breast cancer treated with breast-conserving therapy. Int J Radiat Oncol Biol Phys 2007, 69:1124-30.

9. Baglan $\mathrm{KL}$, Sharpe $M B$, Jaffray $D$, Frazier $R C$, Fayad J, Kestin $L L$, Remouchamps V, Martienz AA, Wong J, Vicini FA: Accelerated partial breast irradiation using 3D conformal radiation therapy (3D-CRT). Int J Radiat Oncol Biol Phys 2003, 55:302-11.

10. Formenti SC, Truong MT, Goldberg JD, Mukhi V, Rosenstein B, Roses D, Shapiro R, Guth A, Dewyngaert : Prone accelerated partial breast irradiation after breast-conserving surgery: preliminary clinical results and dose-volume histogram analysis. Int J Radiat Oncol Biol Phys 2004, 60:493-504.

11. Vicini FA, Remouchamps $V$, Wallace $M$, Sharpe $M$, Fayad J, Tyburski $L$, Letts N, Kestin L, Edmundson G, Pettinga J, Goldstein NS, Wong J: Ongoing clinical experience utilizing 3D conformal external beam radiotherapy to deliver partial-breast irradiation in patients with early-stage breast cancer treated with breast-conserving therapy. Int J Radiat Oncol Biol Phys 2003, 57:1247-53.

12. Taghian AG, Kozak KR, Doppke KP, Katz A, Smith BL, Gadd M, Specht M, Hughes K, Braaten K, Kachnic LA, Recht A, Powell SN: Initial dosimetric experience using simple three-dimensional conformal external-beam accelerated partial-breast irradiation. Int J Radiat Oncol Biol Phys 2006, 64:1092-99.

13. Case RB, Sonke JJ, Moseley DJ, Kim J, Brock KK, Dawson LA: Inter- and intrafraction variability in liver position in non-breath-hold stereotactic body radiotherapy. Int J Radiat Oncol Biol Phys 2009, 75:302-08.

14. Brock KK, Hawkins M, Eccles C, Moseley JL, Moseley DJ, Jaffray DA, Dawson LA: Improving image-guided target localization through deformable registration. Acta Oncol 2008, 47:1279-85.

15. Wang J, Bai $S$, Chen $N, X u$ F, Jiang $X$, Li $Y, X u$ Q, Shen $Y$, Zhang $H$, Gong $Y$, Zhong $R$, Jiang $Q$ : The clinical feasibility and effect of online cone beam computer tomography-guided intensity-modulated radiotherapy for nasopharyngeal cancer. Radiother Oncol 2009, 90:221-27.

16. Marchant TE, Amer AM, Moore CJ: Measurement of inter and intra fraction organ motion in radiotherapy using cone beam CT projection images. Phys Med Biol 2008, 53:1087-98.

17. Sripadam R, Stratford J, Henry AM, Jackson A, Moore CJ, Price P: Rectal motion can reduce CTV coverage and increase rectal dose during prostate radiotherapy: A daily cone-beam CT study. Radiother Oncol 2009, 90:312-17.

18. Moran MS, Lund MW, Ahmad M, Moseley D, Waldron K, Gregory J, Friedman FP, Wilson LD: Clinical implementation of prostate image guided radiation therapy: a prospective study to define the optimal field of interest and image registration technique using automated x-ray volumetric imaging software. Technol Cancer Res Treat 2008, 7:217-26.

19. Purdie TG, Bissonnette JP, Franks K, Bezjak A, Payne D, Sie F, Sharpe MB, Jaffray DA: Cone-beam computed tomography for on-line image 
guidance of lung stereotactic radiotherapy: localization, verification, and intrafraction tumor position. Int J Radiat Oncol Biol Phys 2007, 68:243-52.

20. White EA, Cho J, Vallis KA, Sharpe MB, Lee G, Blackburn H, Nageeti T, McGibney C, Jaffray DA: Cone beam computed tomography guidance for setup of patients receiving accelerated partial breast irradiation. Int $J$ Radiat Oncol Biol Phys 2007, 68:547-54.

21. van Herk M: Errors and Margins in radiotherapy. Semin Radiat Oncol 2004, 14:52-56.

22. van Herk M, Remeijer $P$, Rasch C, Lebesque JV: The probability of correct target dosage: dose-population histograms for deriving treatment margins in radiotherapy. Int I Radiat Oncol Biol Phys 2000, 47:1121-35.

23. Fatunase T, Wang Z, Yoo S, Hubbs JL, Prosnitz RG, Yin FF, Marks LB: Assessment of the residual error in soft tissue setup in patients undergoing partial breast irradiation: results of a prospective study using cone-beam computed tomography. Int I Radiat Oncol Biol Phys 2008, 70:1025-34.

24. Sykes JR, Amer A, Czajka J, Moore CJ: A feasibility study for image guided radiotherapy using low dose, high speed, cone beam X-ray volumetric imaging. Radiother Oncol 2005, 77:45-52.

25. Weed DW, Yan D, Martinez AA, Vicini FA, Wilkinson TJ, Wong J: The validity of surgical clips as a radiographic surrogate for the lumpectomy cavity in image-guided accelerated partial breast irradiation. Int J Radiat Oncol Biol Phys 2004, 60:484-92.

26. Topolnjak R, van Vliet-Vroegindeweij C, Sonke JJ, Minkema D, Remeijer $P$, Nijkamp J, Elkhuizen P, Rasch C: Breast-conserving therapy: radiotherapy margins for breast tumor bed boost. Int J Radiat Oncol Biol Phys 2008, 72:941-48.

doi:10.1186/1748-717X-5-96

Cite this article as: Cai et al: Impact of residual and intrafractional errors on strategy of correction for image-guided accelerated partial breast irradiation. Radiation Oncology 2010 5:96.

\section{Submit your next manuscript to BioMed Central and take full advantage of:}

- Convenient online submission

- Thorough peer review

- No space constraints or color figure charges

- Immediate publication on acceptance

- Inclusion in PubMed, CAS, Scopus and Google Scholar

- Research which is freely available for redistribution

Submit your manuscript at www.biomedcentral.com/submit 